\title{
Correction to: Neotype designation and re-description of Forsskål's reticulate whipray Himantura uarnak
}

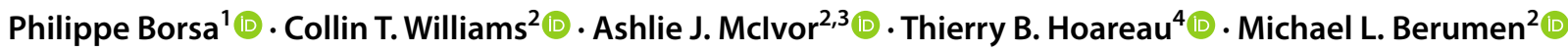

Published online: 5 May 2021

(c) Senckenberg Gesellschaft für Naturforschung 2021

\section{Erratum to : Marine Biodiversity (2021) 51:28 \\ https://doi.org/10.1007/s12526-021-01180-1}

The online version of this article contained a number of typesetting errors which the editor wished to rectify, but it was inadvertently sent for publication before the required corrections were implemented. The publisher would like to apologize for this mistake.

The original article has been corrected.

Publisher's note Springer Nature remains neutral with regard to jurisdictional claims in published maps and institutional affiliations.

The original article can be found online at https://doi.org/10.1007/ s12526-021-01180-1

Philippe Borsa

philippe.borsa@ird.fr

1 Institut de recherche pour le développement, IRD-UMR 250

'Écologie marine tropicale des océans Pacifique et Indien',

34394 Montpellier, France

2 Division of Biological and Environmental Science and Engineering, Red Sea Research Center, King Abdullah

University of Science and Technology (KAUST),

Thuwal 23955-6900, Saudi Arabia

3 MARE - Marine and Environmental Sciences Centre, Agência Regional Para o Desenvolvimento da Investigação Tecnologia E Inovação (ARDITI), Edifício Madeira Tecnopolo, Caminho da Penteada, 9020-105 Funchal, Madeira, Portugal

4 Department of Biochemistry, Genetics and Microbiology, University of Pretoria, X20, Hatfield, 0028 Pretoria, South Africa 